\title{
Influences on Public Transport Utilization: The Case of Auckland
}

\author{
Mark R. Greer, Dowling College \\ Bart van Campen, The Energy Centre \\ The University of Auckland Business School
}

\begin{abstract}
Regression analysis is applied to cross-sectional data for 318 census area units served by the public transportation system in Auckland, New Zealand. The goal is to ascertain the determinants of public transport patronage for the purpose of commuting to work in the region. The analysis addresses both the modifiable areal units problem and spatial autocorrelation. Elasticity estimates are derived for a number of hypothesized drivers of patronage. The paper shows that adjusting for spatial autocorrelation improves the fit of the regression model to the data, a finding that should be of interest to public transportation planners and analysts working with cross-sectional data of a geographic nature.
\end{abstract}

\section{Overview}

This paper applies regression analysis to cross-sectional data, derived largely from the 2006 New Zealand census, for 318 census area units served by the public transportation (PT) system in Auckland, New Zealand. The goal is to ascertain the determinants of PT ridership for the purpose of commuting to work in the region. The paper addresses both the modifiable areal units problem (MAUP) and spatial autocorrelation. The analysis indicates that PT utilization responds positively to an increase in the total number of commuters within a census area unit, an increase in population density, and an increase in service frequency. It responds negatively 
to an increase in automobile ownership rates, an increase in the distance from where commuters live to the nearest commuter rail or ferry station, an increase in distance to the central business district, and an increase in household income. However, only the total commuters, car ownership, station distance, and service frequency variables have statistically significant parameter estimates.

This paper and the time-series analysis by Wang (2009) are among the first to analyze in such detail the drivers of PT use in Auckland. This paper also complements the existing literature in the field by using data on how commuters actually traveled to work, rather than stated preference data, which may not accurately reflect what commuters would actually do in a hypothetical situation posed in a survey. Much of the existing research on this topic uses the latter type of data. It is also one of the first such studies to correct for spatial autocorrelation, which strengthens the regression model.

The merit of the cross-sectional approach used here is that it capitalizes on the variation in economic and demographic data between area units to estimate the impact of each of these variables on PT ridership by commuters from these area units. By the same token, however, it is incapable of measuring the impact of variables that do not vary by area unit, e.g., fuel prices and transit fares, on PT utilization. $^{2}$

\section{Public Transportation in Auckland}

Auckland has been New Zealand's fastest growing region in the recent past, having grown 12.4 percent from 2001 to 2006, which accounts for 54 percent of national growth during this period (ARTA 2007). By 2021, Auckland's population is expected to have grown by 440,000 people and accommodate 37 percent of the national population, as compared to 32 percent of the population in 2006 (ARTA 2007). Rising congestion, increased petrol prices, and heightened concern about air pollution and other externalities, along with a realization that roadway expansion is a costly and often ineffective congestion reduction strategy, have increased public support for improved transport options, including better public transit service (Jakob 2006; Mees and Dodson 2006).

The PT system in Auckland consists of three modes: public bus, commuter rail, and ferry service. The total number of (unlinked) trips taken on the PT system during the fiscal year ending in June 2007 was 52.4 million, with buses, trains and ferries accounting for 82 percent, 10 percent and 8 percent, respectively, of trips 
taken (ARTA 2007). Since 1989 bus, ferry and commuter rail services have been privatized, which has made centralized coordination for the purpose of promoting PT usage problematic (Mees and Dodson 2006). The introduction of inexpensive Japanese car imports has catapulted car ownership rates in New Zealand to the third highest in the world, with 82 percent of the adult population reporting owning a car, compared to 89 percent in the U.S. and 86 percent in Saudi Arabia (Nielsen Company 2007). This contributed to a decline in public transport use from a 15 percent to a 6.2 percent mode share from the late 1980s to 1996, although the share subsequently increased slightly to 6.5 percent by 2006 (ARTA 2007).

Since the end of the 1990s, some measure of re-regulation and coordination has been introduced. Now public bus transportation in Auckland is run by six separate private companies but coordinated by the Auckland Regional Transport Authority (ARTA), which is the implementing body for the transportation strategy of the Auckland Regional Council (ARC) $)^{3}$. ARTA also coordinates the commuter rail and ferry operations.

Since its inception in 2005, ARTA has focused largely on increasing PT use in order to reduce peak car travel and congestion in the region That is, it has a largely commuter focus. Bus services are mostly radial to the central business district (CBD), although Auckland has a relatively dispersed workforce, and only 15 percent of employment in Auckland is within the CBD, as opposed to 19 percent in Christchurch and 22 percent in Wellington (O'Fallon, Sullivan, and Hensher 2004). The overall mode share figures published in a recent ARC Mode Split Research Study show great regional variation; for example, 48 percent of morning peak travelers into the CBD used PT in 2009, as compared to only 9 percent venturing to Manukau in south Auckland (Auckland Transport Blog 2010).

Population growth and increasing levels of affluence in Auckland reinforce the need for high-quality public transportation options. As reported by Litman (2010a), the growth in a metropolitan area's population shifts the composition of potential mass transit users away from transit-dependent users, who are generally low income or persons with disabilities, to discretionary riders, who tend to be more affluent than the captive riders. Moreover, demand for public transport services from higher income, discretionary riders is particularly sensitive to travel time, vehicle comfort, and other dimensions of service quality (Litman 2010a). In fact, in making his case for the superiority of commuter rail over other public transport options, Kenworthy (2008) emphasizes that the superior service quality of rail is what accounts for its ability to attract patronage in relatively affluent 
cities more effectively than other transit options. Wang (2009) confirms that also Auckland rail attracts more affluent patrons. Interestingly, and contrary to common misperception, Kenworthy (2008) also reports cities become more public transport-dependent and less auto-dependent as they grow wealthier. The findings of Kenworthy and Litman certainly reinforce the aforementioned claims made by Jakob, Mees and Dodson.

\section{Data}

The unit of analysis is the New Zealand census area unit, and the point in time for the cross-sectional analysis, is March 6, 2006, the date of the last New Zealand census. There are 398 census area units within the ARC, of which sufficient data could be collected on 318. The sources of data are Statistics New Zealand, Land Transport New Zealand, ARTA, and the University of Auckland. ArcGIS was used in the compilation of data having a spatial dimension.

\section{Dependent Variable}

PT Users - PT users represents the number of people within the census area unit who ticked "public bus," "train," or "other" on the census questionnaire item that asks respondents how the traveled to work on census day. It includes both linked and unlinked trips.

\section{Explanatory Variables}

Total Commuters - The total commuters variable represents the number of people within the census area unit who reported that they had to commute to work on census day. The theoretically expected parameter sign for this variable is positive.

Cars per Household - This variable represents the average number of cars (including trucks) available to a household within the area unit. Its theoretically expected parameter value is negative.

Population Density - The population density variable represents the number of persons per square kilometer within the area unit. Its theoretically expected parameter sign is positive.

Station Distance - This variable represents the shortest overland distance between the centroid of the area unit and the nearest rail or ferry terminal. The exception was certain area units in the far northern suburbs of Auckland, where the authors deemed it unlikely that commuters to the city center would backtrack to a ferry terminal located northeast of them, rather than one located much farther to the 
south, in order to get to work in the city center. The theoretically expected parameter sign for this variable is negative.

Distance to City Center - This variable represents the shortest distance, by road, from the centroid of the area unit to the city center, defined as the intersection of Queen Street and Customs Street downtown. ${ }^{5}$ The more remote area units within the ARC are predominantly rural and contain satellite towns to Auckland City, and commuters in this type of setting are less transit-dependent than those living in metropolitan areas. ${ }^{6}$ The distance-to-city-center variable also serves as a loose proxy variable for the bus and train fare, since the Auckland public bus system uses a stage-based fare scheme for those passengers who do not hold monthly passes. The expected parameter sign for this variable is negative.

Rush Hour Frequency - This variable represents the total number of buses running through and stopping within the area unit, including a 30-meter buffer extending beyond each boundary of the area unit, during the morning and afternoon rush hours combined. Unfortunately, data on service frequency in 2006 for the ferry and rail systems no longer exist, and it was not possible to include these data in the service frequency variable. Given the dominance of the bus system in the overall public transport mode share, with bus trips accounting for 82 percent of public transit trips, however, this may not be a significant handicap. The expected parameter sign of the rush hour frequency variable is positive.

Median Household Income - This variable represents median household income within the area unit. Controlling for the aforementioned car ownership variable, the expected parameter sign for this variable is negative, since, for a given level of car ownership, the more affluent the households are within an area unit, the more affordable is the cost of using a car to get to work. It also is hypothesized that the association, in affluent commuters' minds, of PT, especially public buses, with lower socioeconomic status might deter upper-income commuters from taking PT to get to work.

\section{Analytical Methods and Results}

\section{Simple Log-Log Model}

The first regression model run on the data was a simple log-log one, without adjustment for spatial autocorrelation. It has the following functional form:

$$
\log y_{i}=\beta_{0}+\sum_{j=1}^{m} \beta_{j} \log x_{i j}+\varepsilon_{i}
$$


where $y_{i}$ is the PT users variable, the $x_{i j}$ 's are the explanatory variables, and $\varepsilon_{i}$ is the error term, which is assumed to be independently, identically, and normally distributed with mean zero and constant variance. The betas, of course, are the regression parameters to be estimated. The $i$-subscript refers to the particular census area unit.

The application of the log-log regression model to the data led to the following results indicated in Table 1.

Table 1. Estimated Coefficients, Log-log Regression Model

\begin{tabular}{|l|c|c|c|}
\hline $\begin{array}{l}\text { Independent } \\
\text { Variable }\end{array}$ & $\begin{array}{c}\text { Estimated } \\
\text { Coefficient (b) }\end{array}$ & t-Statistic & $\begin{array}{c}\text { Probability } \\
\text { Value }\end{array}$ \\
\hline Log Tot. Comm. & 1.039 & 15.871 & 0.000 \\
\hline Log Cars per HH & -1.190 & -4.024 & 0.000 \\
\hline Log Pop. Density & 0.032 & 0.975 & 0.330 \\
\hline Log Stat. Distance & -0.052 & -2.207 & 0.028 \\
\hline Log Rush Hr. Freq. & 0.069 & 2.741 & 0.007 \\
\hline Log Dist. City Cent. & -0.463 & -9.240 & 0.000 \\
\hline Log Median Income & -0.099 & -0.938 & 0.349 \\
\hline$R^{2}=0.852$ & $\begin{array}{c}\text { Adjusted } \\
R^{2}=0.849\end{array}$ & $\begin{array}{c}\text { Log Likelihood } \\
=-62.551\end{array}$ & $\begin{array}{c}\text { Link Test Prob. Value } \\
=0.133\end{array}$ \\
\hline
\end{tabular}

The t-statistics have been adjusted for heteroscedasticity using White's heteroscedasticity-consistent errors. The link test is a test for specification error in the form of incorrect functional form and is performed by regressing the dependent variable on its fitted values and the squares of the fitted values. The probability value reported in the table is the significance level of the coefficient estimate for the fitted values squared. One should note that the results have not been adjusted for spatial autocorrelation. Also, the issue of the MAUP remains to be addressed.

As a slight variation on the original model, a modal share model, with the fraction of commuters to work who took PT as the dependent variable, was estimated. The dependent variable was converted to the natural logarithm of the ratio of PT users to total commuters. This model backs out of the R-square calculation the very strong effect of the total commuters variable on the PT users variable, which allows one to ascertain the combined influences of the other regressors on PT usage. Table 2 reports the results when the transformed model is run on the data. 
Table 2. Estimated Coefficients, Log-log Regression Model
Dependent Variable: Log (PT Users/Total Commuters)

\begin{tabular}{|l|c|c|c|}
\hline Independent Variable & Estimated Coefficient (b) & t-Statistic & $\begin{array}{c}\text { Probability } \\
\text { Value }\end{array}$ \\
\hline Log Cars per HH & -1.180 & -4.060 & 0.012 \\
\hline Log Pop. Density & 0.039 & 1.403 & 0.162 \\
\hline Log Stat. Distance & -0.050 & -2.140 & 0.033 \\
\hline Log Rush Hr. Freq. & 0.073 & 3.059 & 0.002 \\
\hline Log Dist. City Cent. & -0.460 & -8.976 & 0.000 \\
\hline Log Median Income & -0.070 & 0.638 & 0.524 \\
\hline$R^{2}=0.666$ & Adjusted $R^{2}=0.659$ & \multicolumn{2}{|c|}{ Log Likelihood $=-63.004$} \\
\hline
\end{tabular}

As can be seen, the fit of the model to the data, as measured by the adjusted $R$-squared, falls, but not precipitously, in the transformed model.

\section{The Modifiable Areal Units Problem}

The modifiable areal units problem (MAUP) has two aspects: the "scale effect" and the "zoning effect." The former refers to the tendency for the results of an analysis of geographic data to depend on the scale of the areal unit used. The zoning effect refers to the tendency for regression results to depend on how the boundaries of the areal units happened to have been drawn, holding the number of areal units constant.

In this paper, no attempt is made to ascertain the significance of the scale effect. The areal unit next smallest to the census area unit is the census meshblock, of which there are 9,855 within the ARC, far too many to make data compilation feasible. The next largest census areal unit beyond the census area unit is the census ward, but there are only 33 of these within the ARC, which is too few to allow statistical inference.

An attempt was made, however, to ascertain the significance of the zoning effect. A synthetic dataset was constructed by using ArcGIS to randomly place one point within each area unit, then interpolate to that point the data from the eight area units whose centroids were closest to the random point, using the inverse distance weighted method with a power factor of 2 . The synthesized dataset contains the same number of records as the original dataset but buffers out to a considerable extent the impact of the arbitrariness of the boundaries of the census area units. The regression analysis was then run on the 318 synthesized datapoints. Table 3 reports the results. 
Table 3. Estimated Coefficients, Log-log Regression Model Synthesized Dataset

\begin{tabular}{|l|c|c|c|}
\hline Independent Variable & Estimated Coefficient (b) & t-Statistic & $\begin{array}{c}\text { Probability } \\
\text { Value }\end{array}$ \\
\hline Log Tot. Comm. & 1.042 & 13.813 & 0.000 \\
\hline Log Cars per HH & -1.345 & -5.767 & 0.000 \\
\hline Log Pop. Density & 0.036 & 1.085 & 0.279 \\
\hline Log Stat. Distance & -0.038 & -1.556 & 0.121 \\
\hline Log Rush Hr. Freq. & 0.095 & 2.819 & 0.005 \\
\hline Log Dist. City Cent. & -0.438 & -9.563 & 0.000 \\
\hline Log Median Income & -0.033 & -0.299 & 0.765 \\
\hline$R^{2}=0.855$ & Adjusted $R^{2}=0.851$ & Log Likelihood $=-3.604$ \\
\hline
\end{tabular}

Once again, White's heteroscedasticity-consistent errors was used to estimate the variances of the parameter estimates.

A comparison of Tables 1 and 3 indicates that, in general, the regression results do not deviate significantly when the analysis is run on the synthetic dataset, as compared to the original results. Each parameter estimate in Table 3 is within one standard error of the corresponding parameter estimate in Table 1, with the exception of the parameter estimates for the rush hour frequency variable, where the difference is 1.04 standard errors. The zoning effect is, thus, unlikely to be substantial in this analysis. The impact of the scale effect, however, remains unknown.

\section{Adjustment for Spatial Autocorrelation}

Spatial autocorrelation occurs when either the value of an explanatory variable in one areal unit is correlated with the value of the variable in contiguous areal units, or when the regression error terms are correlated across contiguous areal units. There is reason to suspect that spatial autocorrelation exists in this study. Consider, for example, the station distance variable. Census area units situated relatively close to a certain rail or ferry station are clustered around that station, and thus around one another. As has been documented in the theoretical literature, e.g., by Anselin (1988), spatial autocorrelation violates certain central tenets of Gaussian linear regression models.

The standard test for spatial autocorrelation is Moran's I, which we applied to the regression residuals in the simple log-log model. ${ }^{7}$ We deemed area units to be contiguous if and only if they shared a common border (which is known rook con- 
tiguity of order 1 ). We next constructed a weight matrix, $\mathbf{W}$, the elements of which are binary, with a 1 in the $w_{i j}^{\text {th }}$ element indicating that the $i^{\text {th }}$ and $j^{\text {th }}$ areal units are contiguous, and a 0 indicating that they are not. Moran's I was then calculated as:

$$
I=\frac{N \sum_{i} \sum_{j} w_{i j}\left(\varepsilon_{i}-\bar{\varepsilon}\right)\left(\varepsilon_{j}-\bar{\varepsilon}\right)}{\left.\sum_{i} \sum_{j} w i_{j}\right) \sum_{i}\left(\varepsilon_{i}-\bar{\varepsilon}\right)^{2}}
$$

where $\varepsilon_{i}$ is the regression residual for the $i^{\text {th }}$ areal unit. Under the null hypothesis of no spatial autocorrelation, the numerator of the expression is zero, and thus so is $I$.

Using the permutation approach described in (Anselin 2005), the value of I turned out to be 0.364 , which has a probability value of less than 0.000 ; therefore, we reject the null hypothesis and conclude that positive spatial autocorrelation exists.

Following Anselin (1992), we adjust for the spatial autocorrelation of the regression residuals by using the spatial errors regression model:

$$
\mathbf{Y}=\mathbf{X} \beta+\varepsilon
$$

where $\mathbf{Y}, \mathbf{X}$ and $\beta$ are the vector of observations on the dependent variable, the matrix of explanatory variables observations by area unit, and the vector of parameters, respectively. $\varepsilon=\gamma \mathbf{W} \varepsilon+\xi$, where $\varepsilon$ is the vector of regression residuals. Each of its elements is spatially autocorrelated with the elements from contiguous area units. The parameter, $\gamma$, which measures the magnitude of this autocorrelation, is one of the coefficients to be estimated. $\xi$, the "white noise" term, is assumed to be normally, identically and independently distributed with mean zero. All variable values are measured in their natural logarithms. Regression equation 3 is estimated using maximum likelihood estimation rather than least squares.

In deciding on a criterion for contiguity for purposes of model estimation, a datadriven approach was pursued and various orders of rook contiguity were applied to the data. Each time, equation 3 was estimated using a different order of contiguity in constructing the weight matrix. Rook order 2, including the lower order of 1 , provided the best fit to the data.

Table 4 reports the regression results from the spatial errors model: 


\section{Table 4. Parameter Estimates and Significance Levels After Adjustment for Spatial Autocorrelation}

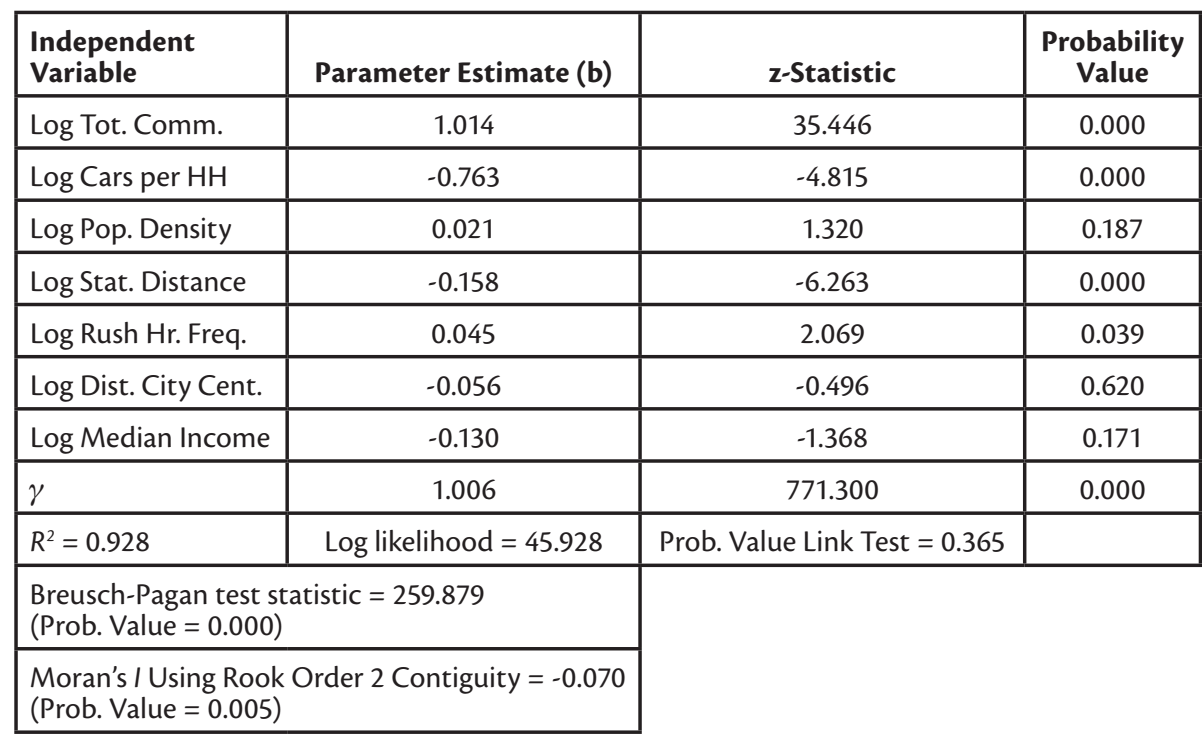

The $R$-squared statistic should be interpreted with extreme caution in a maximum likelihood context, but is reported in case the reader wishes to know it. The maximum likelihood statistic, which is -62.551 in the case of the simple log-log model, provides a better standard for evaluating which model fits the data better. Obviously, the model adjusted for spatial autocorrelation fits the data better.

The Breusch-Pagan statistic indicates the presence of heteroscedasticity. Unfortunately, there is currently no known procedure of which the authors are aware for adjusting for heteroscedasticity in a spatial errors model.

One puzzling statistic is that Moran's I remains statistically significant after the adjustment for spatial autocorrelation. Moreover, it is negative, which is indicative of a systematic tendency for the adjusted residuals to negatively correlate across contiguous area units. The authors are unable to conjure any sort of economic, demographic, or geographic principle that would lead to such negative autocorrelation. In absolute value, though, the magnitude of the Moran's I statistic is very small, and its low probability value may stem in part from the rather large sample size of 318 .

There are some notable differences between the parameter estimates derived from the model with spatial autocorrelation and those derived from the simple log-log 
model. After adjusting for spatial autocorrelation, the estimated impact of the car access variable becomes much weaker than before, the station distance variable much stronger, and the rush hour service frequency variable weaker. All variables continue to have the expected signs, however. In light of the relative merits of the model adjusted for spatial autocorrelation over the simple model, we place much more credence on the parameter estimates derived from the former than those derived from the latter.

\section{Summary Observations on Analytical Findings}

All references to results in this subsection refer to the results in Table 4. All the parameter values have the theoretically-expected signs. However, somewhat unexpectedly, the parameter estimates for the population density, distance from city center, and income variables do not deviate from zero by a statistically significant margin. In an earlier version of this research project, when the dependent variable was bus ridership only, these variables had statistically significant parameter estimates of the expected signs. ${ }^{8}$ This indicates that distance plays a different role in determining bus patronage than ferry and rail patronage in Auckland. It also indicates that income levels have a much stronger negative influence on bus patronage than rail or ferry patronage, a finding that is consistent with the aforementioned reports by Kenworthy (2008) and Litman (2010a).

In interpreting Table 4, the reader is cautioned, however, that there may be an endogeneity problem with the bus service frequency variable. As Holmgren (2007) points out, variables reflecting the extent of PT service actually may be partly endogenous, since public transport providers gear service levels to ridership. Unfortunately, since there currently exist no econometric technique for testing and adjusting for endogeneity within the context of a cross-sectional spatial errors regression model, no such tests or adjustments are undertaken here, and the reader is left with a warning about this potential problem.

\section{Discussion and Relationship to Existing Literature}

Many international studies have been done on the determinants of PT ridership. Recently, new studies and some thorough literature reviews have been issued (e.g., Balcombe 2004; Litman 2004: Litman 2010b; Bresson 2004). Two studies were found related to New Zealand. One, using stated preference experiments for Auckland, Wellington, and Christchurch, focuses on factors and potential policy tools that could influence car commuters to shift modes (O'Fallon, Sullivan, and Hensher 
2004). The results are interesting, but not exactly comparable. The other (Wang, 2009) uses a time-series approach to model rail and bus patronage over 1997-2008 in the Auckland, Wellington, and Christchurch regions using service, fare, car ownership, and income and fuel prices as independent variables. Each city, having different structural, historic, and institutional characteristics impacting on PT use, returned quite different elasticities. Alas, the dataset for Auckland had several limitations, leading to incomplete or insignificant elasticities for fare, car ownership, and income and fuel price variables and therefore is of limited comparative use. ${ }^{9}$

Our results found here do tend to corroborate certain other, international research that has been done in the field and have the expected signs, although elasticities may vary slightly..$^{10}$ The car ownership influence found in our study is similar to others, e.g., Dargay and Hanly (2002) and Zhao et al (2005). Vance and Hedel (2007), using recent German data, report that car usage responds positively — and, presumably, PT ridership negatively - to cars per licensed driver and income among the individuals within their dataset. Bresson et al. (2004) report that rising incomes and increasing motor vehicle penetration both adversely impact PT ridership, although the former influence appears to operate primarily through the motorization effect. As mentioned previously, in an earlier version of this paper on bus patronage only, our analysis clearly showed a separate effect of income from car ownership. Wang (2009) shows a strong impact of car ownership rates in Auckland on bus patronage, but a statistically insignificant one on rail patronage.

Bresson et al. (2004) use different techniques to calculate elasticities for frequency. Short-run elasticities for frequency are around 0.18 , which is fairly inelastic, as found in our study. Litman (2004) notes that the average of previously estimated and published elasticities of PT ridership with respect to service frequency (both peak and non-peak) is about 0.5 , with the higher estimates usually found in cases where service is infrequent. Although higher than the elasticity calculated here, this average of previously estimated elasticities has the same sign as that found here. ${ }^{11}$ The results reported in Evans (1999), Kain and Liu (1999), and Vande Walle and Steenberghen (2006) imply that frequency is an important driver of PT ridership.

\section{Conclusions}

The findings of this article entail certain policy implications for promoting PT patronage in Auckland. We caution the reader, however, about applying our results to PT planning in other cities, since the findings of Nijkamp and Pepping (1998), 
Hensher (2008), and Wang (2009) show that PT elasticities vary considerably from one region to another. Therefore, while we encourage PT planners in other cities to consider adopting our analytical techniques, including the adjustment for spatial autocorrelation and test for the MAUP, local data should be used to estimate the elasticities.

At first glance, the low estimated elasticity for the service frequency variable (each $1 \%$ increase in service frequency within an area unit causes only a $0.045 \%$ increase in patronage) might lead one to believe that increasing service frequency during rush hour, beyond its current level in Auckland, would not be cost effective. However, one should bear in mind that the unit of analysis is one area unit, and that an additional service run during rush hour would certainly increase frequency in more than one area unit and probably in several. Therefore, even with a low estimated elasticity for the service frequency variable, the increase in number of patrons brought about through the addition of one more service run during rush hour may be quite substantial, depending on route, and more than enough to justify the cost of an additional run.

The estimated elasticity for the car ownership variable indicates that policies to discourage automobile ownership could be fairly effective at promoting PT patronage in Auckland, since it indicates that each 1 percent reduction in cars per household boosts PT patronage by about 0.763 percent. Such policies could include policies that raise the cost of owning a car, such as a substantial increase in vehicle registration fees for cars that are registered to an Auckland address and policies that make vehicle ownership less useful, such as a curtailment in central business district parking spaces.

The estimated elasticity for the station distance variable has interesting implications for policies to promote PT usage in Auckland. The station distance variable measures commuter access to Auckland's commuter rail and ferry system, not to its public bus system. Kenworthy (2008) and Litman (2010a) note how rail stations tend to promote the development of mixed-use, compact development in their immediate environs, which, in turn, promotes PT usage. As mentioned earlier in this paper, they also note how commuter rail systems tend to attract affluent, discretionary riders more effectively than bus systems. The same logic would apply to ferry stations, since ferries offer travel times and comfort levels similar to commuter rail. The statistically significant and negative parameter estimate for the station distance variable indicates that further growth of the commuter rail and ferry systems could, over time, positively impact PT patronage in Auckland. ${ }^{12}$ Our 
elasticity estimate indicates that each 1 percent reduction in the distance between the centroid of an area unit and the closest rail or ferry terminal increases PT patronage by about 0.158 percent.

\section{Endnotes}

${ }^{1}$ Every five years, a national census survey is completed in New Zealand, including questions on transport used to travel to work on census day.

${ }^{2}$ Wang (2009), using a time-series approach, addresses these issues.

${ }^{3}$ Since November 1, 2010, the six City Councils and one Regional Council making up the greater Auckland region have been amalgamated into one "Auckland Supercity." ARTA has been renamed Auckland Transport but, as most documentation relevant for this study still has the old ARTA-reference, we continue to refer to ARTA.

${ }^{4}$ There was no category for ferry on this item. Considering the otherwise exhaustive nature of the categories and the prominence of the ferry in Auckland's mass transportation system, this study assumes that a respondent who ticked "other" was a ferry rider.

${ }^{5}$ Dr. Stuart Mitchell of the Department of Engineering Sciences of the University of Auckland deserves credit for making these calculations.

${ }^{6}$ Litman (2004) mentions some reasons why commuters in small cities are less transit-dependent than those in large cities.

7 The diagnostic tests recommended by Anselin (2005) indicated that spatial autocorrelation of the regression residuals was a greater problem than spatial autocorrelation of the regressors.

${ }^{8}$ The station distance variable had a positive estimated coefficient in that case, as would be expected when the dependent variable excluded rail and ferry patronage. The results from the earlier version of this work are available on request from the authors.

${ }^{9}$ Interestingly, Wang (2009) finds that inflation-adjusted (real) fares do not have a statistically significant impact on bus patronage in Auckland and speculates that the high concentration of international students and other PT-dependent users accounts for this. 
${ }^{10}$ General conclusions from these studies are that long-term elasticities are signifcantly higher than short-term elasticities, and that the full effect of major changes in routes, frequency, etc., take 1 to 3 years to show their full effect. As this study does not refer to intertemporal but to geographic variation between (established) neighborhood demographics and factors, one should exercise caution in comparing the elasticities found here with those found in time-series analyses.

${ }^{11}$ One should also be mindful that the 0.5 average of previously-published estimates includes the estimates from low-frequency service areas, where elasticities have generally been found to be high. By contrast, the 0.045 estimate found here is only for rush hour, when frequency is high.

${ }^{12}$ Subsequent to 2007, a bus rapid transit corridor connecting the northern suburbs of Auckland to the CBD opened. The travel speed on this corridor is comparable to commuter rail, and the stations and buses are new, comfortable, and attractive. Therefore, the findings concerning the station distance variable also may apply to the new bus rapid transit corridor, since it is so similar in essential ways to a commuter rail corridor.

\section{Acknowledgment}

The authors would like to thank the anonymous referee for very helpful feedback on an earlier version of the manuscript.

\section{References}

Anselin, L. 1988. Spatial Econometrics: Methods and Models. Klewer Academic Publishers, Dordrech, The Netherlands.

Anselin, L. 1992. Spatial data analysis with GIS: An introduction to application in the social sciences. Technical Report 92-10. National Center for Geographic Information and Analysis, University of California, Santa Barbara, California.

Anselin, L. 2005. Exploring Spatial Data with Geoda: A Workbook. Center for Spatially Integrated Social Science, the University of Illinois, Urbana-Champaign, Illinois.

ARTA. 2007. Annual report 2006/07. Auckland Regional Transport Authority, Auckland, New Zealand. 
Auckland Transport Blog. 2010. http://transportblog.co.nz/2010/03/22/how-togrow-pt-patronage/.

Balcombe R., ed. 2004. The Demand for Public Transport: A Practical Guide. TRL Limited, Birkshire, UK.

Bresson, G., J. Dargay, J. Madre, and A. Pirotte. 2004. Economic and structural determinants of the demand for public transport: An analysis on a panel of French urban areas using shrinkage estimators. Transportation Research Part A 38: 269-285.

Dargay, J., and M. Hanly. 2002. Bus patronage in Great Britain - econometric analysis. Transportation Research Record 1799: 97-106.

Evans, J. 1999. Transit Scheduling and Efficiency, Traveler Response to Transportation System Changes. Transportation Research Board, Washington, D.C.

Hensher, D. 2008. Assessing systematic sources of variation in public transport elasticities: Some comparative warnings. Transportation Research Part A 42: 1031-1042.

Holmgren, J. 2007. Meta-analysis of public transport demand. Transportation Research Part A 41: 1021-1035.

Jakob, A., J. Craig, and G. Fisher. 2006. Transport cost analysis: A case study of the total costs of private and public transport in Auckland. Environmental Science and Policy 9: 55-66.

Kain, J., and Z. Liu. 1999. Secrets of success: Assessing the large increases in transit ridership achieved by Houston and San Diego transit providers. Transportation Research Part A 33: 601-624.

Kenworthy, J. 2008. An international review of the significance of rail in developing more sustainable urban transport systems in higher income cities. World Transport Policy \& Practice 14: 21-37.

Litman, T. 2004. Transit price elasticities and cross-elasticities. Journal of Public Transportation 7: 37-58.

Litman, T. 2010a. Evaluating Public Transit Benefits and Costs: Best Practices Guidebook. Victoria Transport Policy Institute, Victoria, British Columbia.

Litman, T.. 2010b. Transportation Elasticities: How Prices and Other Factors Affect Travel Behavior. Victoria Transport Policy Institute, Victoria, British Columbia. 
Mees, P. and J. Dodson. 2006. Backtracking Auckland: Bureaucratic rationality and public preferences in transport planning, Urban Research Program - Issues Paper 5, Griffith University, Brisbane, Australia.

Nielsen Company 2007. Americans lead the world in car ownership, China and India fast catching up in absolute number of cars owned (press release). http:// my.nielsen.com/news/20070529.shtml, (accessed November 27, 2010).

Nijkamp, P., and G. Pepping. 1998. Meta-analysis for explaining the variance in public transport demand elasticites in Europe. Journal of Transportation and Statistics 1: 1-14.

O'Fallon, C., C. Sullivan and D. Hensher. 2004. Constraints affecting mode choices by morning car commuters. Transport Policy 11: 17-29.

Vance, C., and R. Hedel. 2007. The impact of urban form on car travel: Disentangling causation from correlation. Transportation 34: 575-588.

Vande Walle, S., and T. Steenberghen. 2006. Space and time related determinants of public transport use in trip chains. Transportation Research Part A 40: 151162.

Wang, J. 2009. Appraisal of factors influencing public transport patronage in New Zealand. Paper presented at the 32nd Australasian Transport Research Forum, Auckland, New Zealand. http://www.patrec.org/web_docs/atrf/ papers/2009/1805_paper101-wang.pdf (accessed December 12, 2010).

Zhao, F., L. Chow, M. Li, and X Liu. 2005. A Transit Ridership Model Based on Geographically Weighted Regression and Service Quality Variables. Lehman Center for Transportation Research, Florida International University, Miami, Florida. http://lctr.eng.fiu.edu/re-project-link/finalDO97591_BW.pdf (accessed December 12, 2010).

\section{Authors' Contributions}

Mark Greer is the primary contributor to the sections of the paper pertaining to the data and the analytical methods and results. Bart vanCampen is the primary contributor to the sections pertaining to the public transportation system in Auckland and the discussion and relationship to the existing literature. The remaining sections represent a joint contribution by the authors. 


\section{About the Authors}

MARK R. GReER (greerm@dowling.edu) received his Ph.D. in Economics from the University of Michigan in 1990. He now serves as a professor of economics at Dowling College in New York State and is an honorary research fellow at the Energy Centre of the University of Auckland. He has published articles in the fields of aviation economics, environmental economics, the history of economic thought, and macroeconomic forecast evaluation.

BART VAN CAMPEN (b.vancampen@auckland.ac.nz) holds a master's degree in Energy Engineering from the Eindhoven University of Technology and a master's degree in Public Administration from the Erasmus University Rotterdam (both The Netherlands). He now works as a research fellow for the Energy Centre at the University of Auckland Business School (New Zealand), focusing on energy and transport markets and policy. 